\title{
EFEITO RESIDUAL DA ADUBAÇÃO POTÁSSICA DO AZE VÉ M SOBRE O ARROZ SUBSEQÜENTE EM PLANTIO DIRETO(1)
}

\author{
M. A. SIMONETE ${ }^{(2)}$, L. C. VAHL ${ }^{(3)}$, R. T. FABRE $^{(4)}$, \\ J.R. R. COUTO(5) \& R. LUNARDI ${ }^{(6)}$
}

\begin{abstract}
RESUMO
Com o objetivo de avaliar o efeito residual da adu bação potássica do azevém sobre $o$ arroz subseqüente, em sistema de semeadura direta, foi desenvolvido um experimento de campo, no período de maio de 1996 a abril de 1997, no Centro Agropecuário da Palma-UF Pel, localizado no município do Capão do Leão (RS). Foi utilizado um Planossolo pertencente à unidade de mapeamento Pelotas. Os tratamentos constituíram-se por três níveis de $\mathrm{K}$ aplicados no azevém, equivalentes a 0, 0,5 e 1 vez a dose recomendada de $70 \mathrm{~kg} \mathrm{ha}^{-1}$ de $\mathrm{K}_{2} \mathrm{O}$, sobre cada um dos quais foram aplicados quatro níveis de $\mathrm{K}$ no arroz, cultivado após o azevém, equivalentes a 0, 0,5, 1 e 1,5 vez a dose recomendada de $60 \mathrm{~kg} \mathrm{ha}^{-1}$ de $\mathrm{K}_{2} \mathrm{O}$, resultando num fatorial completo com 12 tratamentos. $\mathrm{O}$ delineamento utilizado foi o de blocos ao acaso com três repetições. Os resultados obtidos indicaram que: (a) o K disponível após as culturas não aumentou neste solo com a adubação potássi ca nas doses recomendadas; (b) o efeito resi dual da adu bação potássica do azevém para a cultura seguinte, neste solo, equivaleu a pelo menos $56 \%$ do potássio aplicado, contido na parte aérea do azevém.
\end{abstract}

Termos de indexação: arroz, azevém, rotação de culturas.

(1) Parte da Tese de Mestrado, apresentada pela primeira autora à Faculdade de Agronomia "Eliseu Maciel" - FAEM/UF Pel, Pel otas (RS). Recebido para publicação em março de 1998 e aprovado em fevereiro de 2002.

(2) Doutoranda em Solos e Nutrição de Plantas, Escola Superior de Agricultura "Luiz de Queiroz" ESALQ/USP. Caixa Postal 09, CEP 13418-900 Piracicaba (SP). E-mail: maapasi@ig.com.br

(3) Professor Titular do Departamento deSol os, Faculdade deAgronomia “Eliseu Maciel" - FAEM/UF Pel. Caixa Postal 354, CEP 96001000 Pel otas (RS). E-mail: Icvahl@conex.com.br

(4) Laboratorista do Departamento deSolos da Faculdade deAgronomia “Eliseu Maciel”- FAEM/UF Pel. Caixa Postal 354, CEP 96001000 Pelotas (RS).

(5) Engenheiro Agrônomo. BUNGE Fertilizantes-Divisão Serrana. E-mail: bungelv@terra.com.br

(6) Engenheiro Agrônomo. Universidade Federal do Rio Grande do Sul - UFRGS. Caixa Postal 776, CEP $90001-970$ Porto Alegre (RS). E-mail:rlunardi@vortex.br 


\title{
SUMMARY: RESIDUAL EFFECT OF POTASSIUM FERTILIZATION WITH RYEGRASS ON SUBSEQUENT RICE UNDER NO-TILLAGE
}

\begin{abstract}
To evaluateresidual effects of potassi um fertilization throught ryegrass on subsequent rice, under no-tillage system, a field experiment was performed from May 1996 to April 1997 in the Agricultural Center (Centro Agropecuário) of Pal ma/ UFPel, in the county of Capão do Leão, Rio Grande do Sul State, Brazil. The examined soil was a Planossolo (Albaqualf) bel onging to the Pel otas mapping unit. Treatments consisted of three $\mathrm{K}$ levels applied on the ryegrass $\left(0,0.5\right.$ and 1 time the recommended dose of $\left.70 \mathrm{~kg} \mathrm{ha}^{-1} \mathrm{~K}_{2} \mathrm{O}\right)$ and four $\mathrm{K}$ levels on the rice grown after the ryegrass (equivalents to $0,0.5,1$ and 1.5 times the recommended dose of $60 \mathrm{~kg} \mathrm{ha}^{-1} \mathrm{~K}_{2} \mathrm{O}$ ), resulting in completefactorial of twel vetreatments. The design used was a randomized block with three replicates. The results indicated that: (a) theavail abl eK after thecultures does not increasein this soil with potassium fertilization in the recommended dosages; (b) the ryegrass potassium fertilization residual effect to the following culture, in this soil, is equivalent, at least, to $56 \%$ of the applied potassium contained in the aerial part of ryegrass.
\end{abstract}

Index terms: rice, ryegrass, potassium, no-tillage, crop rotation.

\section{INTRODUÇÃO}

Dentre os fatores de produção que contribuem para altos rendimentos, os fertilizantes potássicos assumem importância destacada, visto que, depois do nitrogênio, o potássio é o el emento exigido em maior quantidade pelas plantas. No entanto, a eficiência da adubação potássica no sistema de cultivo convencional émuito baixa, situando-se entre 20 e $40 \%$ do total de potássio adicionado (Lopes \& Tedesco, 1991).

A adubação do solo durante a operação de semeadura do arroz torna esta operação demorada e, portanto, mais cara do que a semeadura realizada de forma isolada. Logo, a diminuição da adubação de base resulta em maior rendimento da operação de semeadura, diminuindo os custos da lavoura.

O sistema plantio direto na cultura do arroz irrigado por inundação vem sendo adotado por muitos produtores, como forma alternativa de minimizar o custo de produção. Neste sistema, o arroz é cultivado em rotação com culturas de sequeiro, principalmente em rotação com pastagem, que são utilizadas para a criação extensiva de bovinos.

Atualmente, o azevém é a principal cultura forrageira utilizada como pastagem ou simplesmente para a formação de cobertura morta para a semeadura do arroz. Em geral, as exigências de adubação potássica das culturas de sequeiro são maiores que as da cultura do arroz irrigado por alagamento (Galli, 1994). Logo, no sistema de cultivo azevém-arroz, é possível que os resíduos de potássio aplicado no azevém sejam suficientes para nutrir adequadamente o arroz subseqüente.
Este trabalho teve por objetivo avaliar, em um sistema de rotação de culturas, o efeito residual do potássio aplicado no cultivo do azevém sobre o arroz que o sucede.

\section{MATE RIAL E MÉTODOS}

Foi realizado um experimento de campo, no período de maio de 1996 a abril de 1997, no Centro Agropecuário da Palma-UF Pel, localizado no município de Capão do Leão (RS). Foi utilizado um Planossolo, pertencente à unidade de mapeamento Pelotas, cujas características químicas da camada arável $(0-20 \mathrm{~cm})$ eram as seguintes: $\mathrm{pH}$ em água $(1: 2,5)=5,4 ; \mathrm{P}=3,7 \mathrm{mg} \mathrm{kg}^{-1} ; \mathrm{K}=1,3 \mathrm{mmol}_{\mathrm{c}} \mathrm{kg}^{-1} ; \mathrm{Na}=$ $1,4 \mathrm{mmol}_{\mathrm{c}} \mathrm{kg}^{-1} ; \mathrm{Ca}+\mathrm{Mg}=20,2 \mathrm{mmol}_{\mathrm{C}} \mathrm{kg}^{-1}$ extraídos por Mehlich-1; $\mathrm{H}+\mathrm{Al}=15,4 \mathrm{mmol}_{\mathrm{c}} \mathrm{kg}^{-1}$ determinado pelo tampãoSMP; $\mathrm{Al}=6,8 \mathrm{mmol}_{\mathrm{C}} \mathrm{kg}^{-1}$ extraído por $\mathrm{KCl} 1 \mathrm{~mol} \mathrm{~L}-1$ eMO $=17 \mathrm{~g} \mathrm{~kg}^{-1}$ (Tedesco et al., 1995). A composi ção granul ométrica era: argila $=126 \mathrm{~g} \mathrm{~kg}^{-1}$; silte $=472 \mathrm{~g} \mathrm{~kg}^{-1}$; areia $=402 \mathrm{~g} \mathrm{~kg}^{-1}$, determinada pelo método da pi peta (Day, 1965).

O delineamento utilizado foi o de blocos ao acaso, com parcelas de $3 \times 6 \mathrm{~m}$, espaçadas entre si o suficiente para serem individualizadas por taipas durante o cultivo do arroz. No azevém, os tratamentos foram constituídos por três níveis de potássio aplicados, equivalentes a 0, 0,5 e 1 vez a dose de $70 \mathrm{~kg} \mathrm{ha}^{-1}$ de $\mathrm{K}_{2} \mathrm{O}$ (CFSRS/SC, 1995), com 12 repetições, total izando trinta eseis parcelas. Para o arroz, foram aplicados quatro níveis de potássio, cultivado após o azevém, equivalentes a 0, 0,5, 1 e 1,5 vez a dose de $60 \mathrm{~kg} \mathrm{ha}^{-1}$ de $\mathrm{K}_{2} \mathrm{O}$ (CFSRS/SC, 1995), formando um fatorial completo resultante da 
combinação dos três níveis aplicados no azevém com os quatro níveis aplicados no arroz, com doze tratamentos e três repetições.

Antes de o azevém ser semeado, foram aplicadas as adubações, nitrogenada e fosfatada, em todas as parcelas na forma de uréia ( $35 \mathrm{~kg} \mathrm{ha}^{-1}$ de N) e superfosfato triplo (100 kg ha-1 de $\mathrm{P}_{2} \mathrm{O}_{5}$ ), respectivamente. O potássio foi aplicado na forma de cloreto de potássio conforme os tratamentos. Os adubos foram incorporados na camada arável de $0-5 \mathrm{~cm}$ com enxada rotativa. O azevém foi semeado em 16 de maio de 1996, na densidade de $32 \mathrm{~kg} \mathrm{ha}^{-1}$, e incorporado ao sol o com ancinho. Foi feita adubação nitrogenada de cobertura, na forma de uréia, equivalente a $35 \mathrm{~kg} \mathrm{ha}^{-1}$ de $\mathrm{N}$. No início do florescimento do azevém foram coletadas, da parte aérea de cada parcela, três amostras de 0,0625 $\mathrm{m}^{2}$ para a determinação dos teores de N, P eK e cál culo da produção de matéria seca. No final do ciclo do azevém, foi aplicado dessecante, deixando-se a palhada como cobertura morta, e retiradas amostras de solo de cada parcela nas profundidades de 0-5 e 5-20 cm para determinação do teor de K e calculado o teor médio de potássio da camada de $0-20 \mathrm{~cm}$ em cada parcela.

O arroz (cultivar Chuí) foi semeado em 5 de novembro de 1996, em sistema de semeadura direta em linhas espaçadas entre si de $17,5 \mathrm{~cm}$. Antes da semeadura, foram feitas, em todas as parcelas, adubação nitrogenada ( $30 \mathrm{~kg} \mathrm{ha}^{-1} \mathrm{de} \mathrm{N}$ ), fosfatada (60 kg ha-1 de $\mathrm{P}_{2} \mathrm{O}_{5}$ ) e potássica (de acordo com os tratamentos). As fontes dos adubos foram as mesmas utilizadas para a adubação da cultura do azevém. Na diferenciação do primórdio floral, foi aplicada a adubação nitrogenada de cobertura, equivalente a $30 \mathrm{~kg} \mathrm{ha}^{-1}$ de $\mathrm{N}$ na forma de uréia. Durante a floração plena, foram coletadas folhas bandeira (20 folhas por parcela) para determinar os teores totais deN, P eK. Uma semana após oflorescimento, foram col etadas amostras em 0,5 m de linha com três repetições por parcela da parte aérea do arroz para quantificação da produção de matéria seca e determinação do teor de K (utilizados para cálculo de $\mathrm{K}$ acumulado pelas plantas). No final do ciclo, foram determinados o rendimento de grãos e o teor de potássio disponível no sol o nas profundidades de 0-5 e 5-20 cm, bem como calculado o teor médio de potássio da camada de 0-20 cm em cada parcela.

Os teores de $\mathrm{K}$ disponível das amostras de solo foram obtidos pela extração com Mehlich-1 (Tedesco et al., 1995). As amostras de tecido do azevém e arroz foram secas em estufa a $60^{\circ} \mathrm{C}$, até massa constante, pesadas, moídas e digeridas com uma mistura nitro-perclórica (Tedesco et al., 1995). O teor deK nos extratos foi determinado por fotometria de chama.

Os efeitos dos tratamentos foram avaliados por meio de análise de variância (teste F) e os efeitos das doses de potássio, por regressão polinomial.

\section{RESULTADOS E DISCUSSÃO}

\section{Azevém}

Não houve resposta significativa do azevém à adubação potássica quantoà produção de matéria seca da parteaérea (Quadro 1). No nível zero de potássio, a produção de matéria seca correspondeu a $92 \%$ do máximo obtido com a dose recomendada pela CFSRS/SC (1995), equivalentea $70 \mathrm{~kg} \mathrm{ha}^{-1}$ de $\mathrm{K}_{2} \mathrm{O}$. A ausência de resposta do azevém ao potássio pode ser atribuída ao fato de ser o teor disponível inicial do elemento no solo relativamente el evado $\left(1,28 \mathrm{mmo}_{\mathrm{C}} \mathrm{kg}^{-1}\right)$, queémuito próximo do nível crítico de 1,54 mmol $\mathrm{c} \mathrm{kg}^{-1}$ (CF SRS/SC, 1995). Entretanto, o teor e o acúmulo de potássio pela parte aérea (Quadro 1) aumentaram significativamente com a adubação potássica. O potássio caracteriza-se por ser acumulado pelas plantas em quantidades acima das necessárias, desde que os níveis no solo sejam altos, ou seja, há um "consumo de luxo" (Mengel \& Kirkby, 1982).

O potássio acumulado relacionou-se de forma linear com a dose aplicada (Quadro 1), aumentando, em média, 0,56 kg ha-1 de potássio para cada $\mathrm{kg} \mathrm{ha}^{-1}$ de potássio aplicado como $\mathrm{K}_{2} \mathrm{O}$ no adubo. I sto significa queaproximadamente $56 \%$ do $\mathrm{K}$ do adubo foi acumulado na matéria seca da parte aérea do azevém, no final do cido da cultura, independentemente da dose.

Os teores de $\mathrm{K}$ disponível na camada arável (0$20 \mathrm{~cm}$ ), após o cultivo do azevém, não foram afetados significativamente pela adubação potássica (Quadro 2). Consi derando quea parteaérea continha $56 \%$ do potássio aplicado, a fração restante de $44 \%$ pode ter tomado três destinos: retida pelas raízes, perdida da camada arável $(0-20 \mathrm{~cm})$ por lixiviação, transformada para formas não-trocáveis e/ou fixada, portanto, não-extraíveis pelo método de Mehlich-1 utilizado na análise.

Comparando o teor inicial de $\mathrm{K}$ disponível de $1,28 \mathrm{mmol}_{\mathrm{C}} \mathrm{kg}^{-1}$ na camada arável $(0-20 \mathrm{~cm})$ com o teor de $0,87 \mathrm{mmol}_{\mathrm{C}} \mathrm{kg}^{-1}$ no nível zero de potássio aplicado no final do ciclo da cultura, verifica-se uma diminuição do $\mathrm{K}$ disponível equivalente a $32 \mathrm{~kg} \mathrm{ha}^{-1}$ de $K$. O potássio acumulado na parte aérea neste tratamento foi equivalente a $66 \mathrm{~kg} \mathrm{ha}^{-1}$ de potássio (Quadro 1) e, portanto, $34 \mathrm{~kg} \mathrm{ha}^{-1}$ a mais do que a diminuição do K disponível no solo. Isto significa que aproximadamente metade do potássio acumulado na parte aérea da cultura na ausência de adubação potássica foi proveniente de formas de $\mathrm{K}$ inicialmente não detectadas pelo Mehlich-1. Esta contribuição de K não computado pel o Mehlich-1 foi verificada em outros trabal hos (Oliveira et al., 1971; Lopes et al., 1995; N atale et al., 1996; E spinal, 1997; Simonete et al., 1998), explicando, pelo menos em parte, a ausência de resposta da cultura à adubação potássica neste solo. 
Quadro 1. Produção de matéria seca, teor e quantidade de $K$ acumulada na parte aérea do azevém, considerando as doses de $\mathrm{K}$ aplicadas no solo

\begin{tabular}{cccc}
\hline Dose de $\mathbf{K}$ & Matéria seca & Teor de $\mathbf{K}$ & K acumulado \\
\hline $\mathrm{kg} \mathrm{ha}^{-1}$ de $\mathrm{K}_{2} \mathrm{O}$ & $\mathrm{t} \mathrm{ha-1}$ & $\mathrm{g} \mathrm{kg}^{-1}$ & $\mathrm{~kg} \mathrm{ha}{ }^{-1}$ \\
0 & 9,23 & 7,1 & 66 \\
35 & 9,32 & 8,9 & 83 \\
70 & 10,02 & 10,5 & 105 \\
Probabilidade $>\mathrm{F}$ & $0,1810^{\text {ns }}$ & $0,0003^{* *}$ & $0,0001^{* *}$ \\
Modelo $(\mathrm{Y}=\mathrm{a}+\mathrm{bX})$ & - & $\mathrm{Y}=7,1208+3,4083 \mathrm{X}$ & $\mathrm{Y}=0,557 \mathrm{X}+65,167$ \\
Termo de regressão $\left(\mathrm{R}^{2}\right)$ & 11,65 & 14,17 & $0,995^{* *}$ \\
C.V. (\%) & & 13,72 \\
\hline
\end{tabular}

**, ns Indicam, respectivamente, que os termos foram significativos a $\mathrm{p} \leq 0,01$ e não-significativos pelo Teste $\mathrm{F}$.

Quadro 2. Teor de K disponível no solo, após cultivo do azevém, considerando as doses de K aplicadas no solo

\begin{tabular}{cccc}
\hline \multirow{2}{*}{ Dose de K aplicada no azevém } & \multicolumn{3}{c}{ Teor de K disponível no solo } \\
\cline { 2 - 4 } & $\mathbf{0 - 5} \mathbf{~ c m}$ & $\mathbf{5 - 2 0} \mathbf{~ c m}$ & $\mathbf{0 - 2 0} \mathbf{~ c m}^{(\mathbf{1})}$ \\
\cline { 2 - 3 } $\mathrm{kg} \mathrm{ha}^{-1}$ de $\mathrm{K}_{2} \mathrm{O}$ & & $\mathrm{mmol}_{\mathrm{c}} \mathrm{kg}^{-1}$ & \\
0 & 1,13 & 0,77 & 0,87 \\
35 & 1,20 & 0,76 & 0,87 \\
70 & 1,31 & 0,72 & 0,88 \\
Probabilidade $>\mathrm{F}$ & $0,0042^{* *}$ & $0,5047^{\mathrm{ns}}$ & $0,5216^{\mathrm{ns}}$ \\
Modelo $(\mathrm{Y}=\mathrm{a}+\mathrm{bX})$ & $\mathrm{Y}=1,1183+\mathrm{X} 0,00257$ & - & - \\
Termo de regressão $\left(\mathrm{R}^{2}\right)$ & $0,979^{* *}$ & - & - \\
C.V. (\%) & 10,09 & 16,01 & 10,12 \\
\hline
\end{tabular}

(1) Média ponderada dos teores observados nas profundidades de 0-5 e $5-20 \mathrm{~cm}$.

**, ns Indicam, respectivamente, que os termos foram significativos a $\mathrm{p} \leq 0,01$ e não-significativos pelo Teste $\mathrm{F}$.

\section{Arroz}

Considerando a folha bandeira do arroz na fase de florescimento como indicadora do estado nutricional da planta, pode-se observar que não houve efeito significativo da adubação potássica sobre o teor deste elemento na fol ha bandeira (Quadro 3). I sto significa que sem adubação potássica a planta conseguiu atingir um estado nutricional em potássio semel hante ao atingido com a dose recomendada pela CFSRS/SC (1995).

Quando foi semeado o arroz, o teor médio de potássio na camada arável $(0-20 \mathrm{~cm})$ era de $0,87 \mathrm{mmol}_{\mathrm{C}} \mathrm{kg}^{-1}$ (Quadro 2). Mesmo assim, não houve efeito significativo da adubação potássica na quantidade de potássio acumulado pela parteaérea do arroz e na produção de grãos (Quadro 3); ao contrário do azevém que, mesmo não tendo respondido em produção de matéria seca, acumulou aproximadamente $56 \%$ do K aplicado na parteaérea (Quadro 1). É possível queisto seja uma característica do arroz cultivado em sol o alagado. Estes resultados estão deacordo com os obtidos em outros experimentos que têm demonstrado a baixa resposta do arroz à adubação potássica (L opes et al., 1981; Lopes, 1991; Lopes et al., 1995; Machado et al., 1997; Espinal, 1997).

Machado et al. (1997), avaliando épocas de aplicação de potássio no sistema de cultivo de arroz pré-germinado, em Planossolo da EstaçãoExperimental deTerras Baixas da E mbrapa-CTACT, utilizando dose de $60 \mathrm{~kg} \mathrm{ha}^{-1}$ de $\mathrm{K}_{2} \mathrm{O}$, constataram que não houve resposta da cultura à adubação potássica na quantidade do elemento absorvida pelas plantas e na produção de grãos. Os autores atribuíram a falta de resposta da cultura ao fato de o teor inicial de $\mathrm{K}$ disponível $\left(0,97 \mathrm{mmol}_{\mathrm{C}} \mathrm{kg}^{-1}\right.$ extraído por Mehlich-1) ter sido suficiente para suprir as exigências das 
plantas no primeiro ano de cultivo, corroborando o que observaram Lopes et al. (1995) em pesquisa similar realizada em Planossolo da Estação Experimental de Cachoerinha (RS) (IRGA).

Segundo Nachtigall \& Vahl (1989), em trabal hos realizados sobre solos de várzea do Rio Grande do Sul, tem-se observado a baixa resposta da cultura do arroz irrigado por alagamento à adubação potássica, mesmo com teores de K trocável baixo, o quetalvez se deva aos teores relativamente altos de minerais potássicos encontrados nesses sol os que são fontes de K não-trocável para as culturas. Além do que, a baixa resposta da cultura do arroz irrigado por alagamento quanto à produção de grãos pode estar associada a solos em que o cultivo é feito somente durante um ano, como é o caso deste experimento (Vahl, 1989).
Durante o cultivo do arroz no tratamento com dose zero de adubação potássica, o K disponível diminuiu de 0,87 para $0,76 \mathrm{mmol}_{\mathrm{C}} \mathrm{kg}^{-1}$ na camada arável (0-20 cm) (Quadros 2 e 4, respectivamente), o que equivale apenas $8 \mathrm{~kg} \mathrm{ha}^{-1}$ de potássio. A cultura, entretanto, acumulou na parte aérea aproximadamente $104 \mathrm{~kg} \mathrm{ha}^{-1}$ do el emento (Quadro 3). Mesmo que os $66 \mathrm{~kg} \mathrm{ha}^{-1}$ de potássio contido na palha do azevém (Quadro 1), sobrea qual o arroz foi cultivado, tenham sido utilizados por esta cultura, ainda faltam $30 \mathrm{~kg} \mathrm{ha}^{-1}$ para completar o potássio acumulado pelo arroz, que devem ter saído de formas não extraídas pelo Mehlich-1, o quetambém ocorreu na cultura doarroz.

A absorção de $\mathrm{K}$ não-trocável pelas culturas em solos com teores altos destas formas do elemento é um fato conhecido e estudado por muitos pesquisadores (Nachtgall \& Vahl, 1991; Meurer \& Anghinoni, 1993;

Quadro 3. Teor de K na folha bandeira, K acumulado pela parte aérea e produção de grãos do cultivar de arroz E mbrapa 6 - Chuí, considerando o K aplicado no azevém antecedente e no arroz em sistema plantio direto

\begin{tabular}{|c|c|c|c|c|c|}
\hline \multirow{2}{*}{ Dose de K aplicada no azevém } & \multicolumn{4}{|c|}{ Dose de K aplicada no arroz ( $\mathrm{kg} \mathrm{ha}^{-1}$ de $_{2} \mathrm{O}$ ) } & \multirow{2}{*}{ Média } \\
\hline & $\mathbf{0}$ & 20 & 40 & 60 & \\
\hline $\mathrm{kg} \mathrm{ha}^{-1} \mathrm{~K}_{2} \mathrm{O}$ & \multicolumn{5}{|c|}{ _ Teor de $\mathrm{K}$ na fol ha bandeira, $\mathrm{g} \mathrm{kg}^{-1}$} \\
\hline $\begin{array}{r}0 \\
35 \\
70\end{array}$ & $\begin{array}{l}9,6 \\
9,4 \\
9,9\end{array}$ & $\begin{array}{r}9,8 \\
9,5 \\
10,5\end{array}$ & $\begin{array}{r}9,6 \\
10,0 \\
9,7\end{array}$ & $\begin{array}{r}10,1 \\
9,3 \\
9,7\end{array}$ & $\begin{array}{r}9,9 \\
9,6 \\
10,0\end{array}$ \\
\hline Média & 9,6 & 9,9 & 9,9 & 9,8 & \\
\hline $\begin{array}{l}\text { Variáveis } \\
\text { Dose azevém } \\
\text { Dose arroz } \\
\text { Dose az x dose ar(1) }\end{array}$ & \multicolumn{4}{|c|}{$\begin{array}{c}\text { Probabilidade }>F \\
0,1971^{\text {ns }} \\
0,6466^{\text {ns }} \\
0,2796^{\text {ns }}\end{array}$} & \\
\hline C.V. (\%) & \multicolumn{4}{|c|}{5,61} & \\
\hline & \multicolumn{5}{|c|}{ _ K acumulado, $\mathrm{kg} \mathrm{ha}^{-1}$} \\
\hline $\begin{array}{r}0 \\
35 \\
70\end{array}$ & $\begin{array}{l}103,92 \\
100,76 \\
103,27\end{array}$ & $\begin{array}{r}97,45 \\
110,04 \\
110,38\end{array}$ & $\begin{array}{r}94,03 \\
94,29 \\
125,63\end{array}$ & $\begin{array}{l}109,48 \\
118,02 \\
114,35\end{array}$ & $\begin{array}{l}101,22 \\
105,77 \\
113,41\end{array}$ \\
\hline Média & 102,65 & 105,96 & 104,65 & 113,95 & \\
\hline $\begin{array}{l}\text { Variáveis } \\
\text { Dose azevém } \\
\text { Dose arroz } \\
\text { Dose az x dose ar(1) }\end{array}$ & \multicolumn{5}{|c|}{$\begin{array}{c}\text { Probabilidade }>F \\
0,3555^{\mathrm{ns}} \\
0,6709^{\mathrm{ns}} \\
0,7236^{\mathrm{ns}}\end{array}$} \\
\hline C.V. (\%) & \multicolumn{4}{|c|}{19,16} & \\
\hline & \multicolumn{5}{|c|}{ Produção de grãos, t ha-1 } \\
\hline $\begin{array}{r}0 \\
35 \\
70\end{array}$ & $\begin{array}{l}5,18 \\
4,35 \\
4,02\end{array}$ & $\begin{array}{l}4,43 \\
4,80 \\
4,50\end{array}$ & $\begin{array}{l}4,29 \\
4,06 \\
4,56\end{array}$ & $\begin{array}{l}4,67 \\
4,30 \\
3,95\end{array}$ & $\begin{array}{l}4,64 \\
4,38 \\
4,26\end{array}$ \\
\hline M édia & 4,52 & 4,58 & 4,30 & 4,31 & \\
\hline $\begin{array}{l}\text { Variáveis } \\
\text { Dose azevém } \\
\text { Dose arroz } \\
\text { Dose az x dose ar(1) }\end{array}$ & \multicolumn{5}{|c|}{$\begin{array}{c}\text { Probabilidade }>F \\
0,3728^{n s} \\
0,7564^{n s} \\
0,5223^{n s}\end{array}$} \\
\hline C.V. (\%) & \multicolumn{5}{|c|}{15,21} \\
\hline
\end{tabular}

(1) Dose de K aplicada no azevém (Dose az) x Dose de K aplicada no arroz (Dose ar).

ns Indica que o termo não foi significativo a $\mathrm{p} \leq 0,01$ pelo Teste $F$. 
Quadro 4. Teor de potássio disponível na camada arável do solo $(0-20 \mathrm{~cm})^{(1)}$ após o cultivo do arroz, considerando o potássio aplicado no azevém antecedente e no arroz em sistema plantio direto

\begin{tabular}{|c|c|c|c|c|c|}
\hline \multirow{2}{*}{ Dose de $K$ aplicada no azevém } & \multicolumn{4}{|c|}{ Dose de $\mathrm{K}$ aplicada no arroz (kg ha-1 de $\left.\mathrm{K}_{2} \mathrm{O}\right)$} & \multirow{2}{*}{ Média } \\
\hline & $\mathbf{0}$ & 20 & 40 & 60 & \\
\hline $\mathrm{kg} \mathrm{ha}^{-1} \mathrm{~K}_{2} \mathrm{O}$ & \multicolumn{4}{|c|}{$\mathrm{mmol}_{\mathrm{c}} \mathrm{kg}^{-1}$} & \multirow{5}{*}{$\begin{array}{l}0,73 \\
0,73 \\
0,87\end{array}$} \\
\hline $\begin{array}{r}0 \\
35 \\
70\end{array}$ & $\begin{array}{l}0,76 \\
0,64 \\
0,76\end{array}$ & $\begin{array}{l}0,66 \\
0,76 \\
0,76\end{array}$ & $\begin{array}{l}0,81 \\
0,74 \\
1,02\end{array}$ & $\begin{array}{l}0,67 \\
0,79 \\
0,89\end{array}$ & \\
\hline Média & 0,72 & 0,73 & 0,86 & 0,78 & \\
\hline $\begin{array}{l}\text { Variáveis } \\
\text { Dose azevém } \\
\text { Dose arroz } \\
\text { Dose az x dose ar(2) }\end{array}$ & \multicolumn{4}{|c|}{$\begin{array}{c}\text { Probabilidade }>F \\
0,0587^{n s} \\
0,0607^{n s} \\
0,1439^{n s}\end{array}$} & \\
\hline C.V. (\%) & \multicolumn{4}{|c|}{13,41} & \\
\hline
\end{tabular}

Silva et al., 1995; Natale et al., 1996; Simonete et al., 1999). É comumente concluído, entretanto, que a contribuição destas formas do elemento é mais acentuada quando os teores de K trocável no sol o são baixos (Mielnizuck, 1978). Considerando que o arroz utilizou K não extraído pelo Mehlich-1 e não aumentou o acúmulo do el emento pelas plantas e o teor disponível nosolo, quando foi adicionado potássio como adubo (Quadros 3 e 4, respectivamente), acredita-se que o K aplicado tenha sido perdido por lixiviaçãoe, ou, convertido para formas não-trocáveis. U ma vez que o sol o permaneceu inundado por cerca de $2 / 3$ do ciclo da cultura, parte do $\mathrm{K}$ adicionado ao solo pode ter sido fixada em virtude da alternância de ciclo de alagamento e drenagem.

Os resultados mostram que o efeito residual da adubação potássica do azevém sobre a cultura seguinte está associado ao potássio acumulado nos restos do azevém, uma vez que o $\mathrm{K}$ disponível no solo após o azevém não aumentou com a adubação. Como o potássio contido no tecido das plantas é prontamente disponível para as culturas seguintes, pois a sua liberação não depende da decomposição dos restos vegetais, pode-se inferir que, mesmo quando osoloédeficienteem potássio, situaçãoem que poderia haver resposta do azevém à adubação potássica, o potássio contido na parte aérea desta cultura contribuiria com aproximadamente $56 \%$ do adubo para nutrir, de forma adequada, o arroz cultivado imediatamenteapós no sistema de semeadura direta.

\section{CONCLUSÕES}

1. O K disponível após as culturas não aumentou neste solo com a adubação potássica nas doses recomendadas.
2. O efeito residual da adubação potássica do azevém para a cultura seguinte, neste solo, equivale a pelo menos $56 \%$ do potássio aplicado, contido na parte aérea do azevém.

\section{LITE RATURA CITADA}

COMISSÃO DE FERTILIDADE DO SOLO - CFSRS/SC. Recomendações de adubação e calagem para os estados do Rio Grande do Sul e Santa Catarina. 3.ed. Passo Fundo, SBCS - Núcleo Regional Sul/E MBRAPA-CNPT, 1995. 224p.

DAY, P.R. Particle fractionation and particle size analyses. In: BLACK, C.A. Methods of soil analyses. Madison, American Society Agronomy, 1965. p.499-510.

ESPINAL, F.S.C. Fontes de nitrogênio e épocas de aplicação de potássio em arroz irrigado. Pelotas, Universidade Federal de Pelotas, 1997, 60p. (Tese de Mestrado)

GALLI, K.B. Alterações das propriedades químicas de um Planossolo provocadas por diferentes sistemas de cultivos. Pel otas, Universidade Federal de Pelotas, 1994, 72p. (Tese de Mestrado)

LOPES, M.S.; BACHA, R.E. \& CABRAL, J.T. Calibração de análise de solo para arroz irrigado. In: REUNIÃO GERAL DO ARROZ IRRIGADO, 18., Porto Alegre, 1981. Anais. Pelotas, Unidade de Execução de Pesquisa de Âmbito Estadual de Pelotas, 1981. p.167-169.

LOPES, S.I.G. Eficiência da adubação potássica e distribuição radicular do arroz irrigado. Porto Alegre, Universidade Federal do Rio Grande doSul, 1991. 96p. (Tese de Mestrado)

LOPES, S.I.G.; LOPES, M.S.; BARROS, J .A.I .; OLIVEIRA, M.A.B.; MATTIOLI, F.G. \& HOROWITZ, N. Níveis de aplicação de potássio na cultura de arroz irrigado. In: REUNIÃO DO ARROZ IRRIGADO, 21., Porto Alegre, 1993. Anais. Porto Alegre, Instituto Rio-Grandense doArroz, 1995. p.187-189. 
LOPES, S.I.G. \& TEDESCO, M.J. Eficiência da adubação potássica para arroz irrigado em relação a dose, modo de incorporação e época de aplicação do adubo. In: REUNIÃO DA CULTURA DO ARROZ IRRIGADO, 19., Balneário Camboriú, 1991. Anais. Florianópolis, Empresa Catarinense de Pesquisa Agropecuária., 1991. p.153-155.

MACHADO, M.O.; FRANCO, C.B. \& PETRINI, J.A. Épocas de aplicação de potássio no sistema de cultivo de arroz pré germinado, em duas safras consecutivas. In: REUNIÃO DA CULTURA DO ARROZ IRRIGADO, 22., Balneário Camboriú, 1997. Anais. Itajaí, Empresa de Pesquisa Agropecuária e Difusão de Tecnologia de Santa Catarina, 1997. p.279-281

MENGEL, K. \& KIRKBY, E.A. Potassium. In: PRICIPLES OF NUTRITION. Worblanfin - Bern/Switzerland, I nternational Potash Institute, 1982. 655p.

MEURER, E.J . \& ANGHINONI, I. Disponibilidade de potássio e sua relação com parâmetros de solo. R. Bras. Ci. Solo, 17:377-382, 1993.

MIELNICZUK, J .O Potássio no solo. Piracicaba, Instituto da Potassa-Fosfato, Instituto Internacional da Potassa, 1978. 80p. (Boletim técnico, 2)

NACHTIGALL, G.R. \& VAHL, L.C. Capacidade de suprimento de potássio dos solos da região Sul do Rio Grande do Sul. R. Bras. Ci. Solo, 15:37-42, 1991.

NACHTIGALL, G.R. \& VAHL, L.C. Formas de potássio em solos da região sul do estado do Rio Grande do Sul. R. Bras. Ci. Solo, 13:7-12, 1989.
NATALE, W., MARQUES, J J., BOARETTO, A.E. \& SIMÕES, F.L. Mineralogia e formas de potássio em um latossolo vermel ho-amarelo sob um pomar de goiabeiras. In: CONGRESSO AMERICANO DE CIÊNCIA DO SOLO SOLO-SUELO, 8., Águas de Lindóia, 1996. Anais. Campinas, EMBRAPA-Cerrados, 1996. CD-ROM.

OLIVEIRA, V.; LUDWICK, A.E. \& BEATTY, M.T. Potassium removed from some southern brazilian soils by exhaustive cropping chemical extraction methods. Proc. Soil Sci. Soc. Am., 35:763-767, 1971.

SILVA, D.N.; MEURER, E.J .; KANPF, N. \& BOKET, C.M. Mineralogia e formas de potássio em dois Latossolos do estado do Paraná e suas relações com a disponi bilidade para as plantas. R. Bras. Ci. Solo, 19:249-254, 1995.

SIMONETE, M.A.; VAHL, L.C. \& FABRES, R.T. Capacidade extração de potássio por culturas forrageiras de inverno em planossolo. In: REUNIÃO DE FERTILIDADE DO SOLO E NUTRIÇÃO DE PLANTAS - FERTIBIO, 23., Caxambu, MG, 1998. Anais. Lavras, Sociedade Brasileira de Ciência do Solo, 1998. p.753.

TEDESCO, M.J .; VOLKWEISS, S.J . \& BOHNEN, H. Análises de solo, plantas e outros materiais. 2.ed. Porto Alegre, Universidade Federal do Rio Grande do Sul, 1995. 174p. (Boletim técnico, 5)

VAHL, L.C. Arroz irrigado: culturas brasileiras. Porto Alegre, Adubos Trevo, 1989. 18p. (Circular técnica, 34) 
M.A. SIMONETE et al.

R. Bras. Ci. Solo, 26:721-727, 2002 